\title{
Characterization of the Infarct Pattern Caused by Vulnerable Aortic Arch Atheroma: DWI and Multidetector Row CT Study
}

\author{
Suk Jae Kim ${ }^{a}$ Sookyung Ryoo ${ }^{a}$ Jaechun Hwang ${ }^{a}$ Hyun Jin Noh ${ }^{a}$ \\ Jae Hyun Park ${ }^{a}$ Yeon Hyeon Choe ${ }^{b}$ Oh Young Bang ${ }^{a}$ \\ Departments of a Neurology and ${ }^{\mathrm{b}}$ Radiology, Samsung Medical Center, Sungkyunkwan University \\ School of Medicine, Seoul, Korea
}

\section{Key Words}

Ischemic stroke - Aortic arch atheroma - Diffusion-weighted imaging $\cdot$ Multidetector cardiac computed tomography

\begin{abstract}
Background: Aortic arch atheroma (AAA) has been accepted as a possible embolic source in patients with ischemic stroke, especially cryptogenic stroke. However, despite its well-known role as a risk factor for stroke, research focused on the mechanism or characteristics of stroke caused by AAA is insufficient. In this study, we aimed to evaluate clinical and radiological characteristics including lesion pattern on DWI in acute stroke patients associated with vulnerable AAA detected by multidetector row computed tomography (MDCT). Methods: From September 2008 through May 2011, patients who presented with acute ischemic stroke and underwent MDCT were found in a prospective stroke registry. Patients without evident stroke etiology were included and classified by presence of vulnerable AAA. Vulnerable AAA was defined as (i) at least $6 \mathrm{~mm}$ thick adjacent to the aortic wall; (ii) ulcerated plaque, or (iii) soft plaque. Soft plaque was defined as the presence of clearly visualized area of hypoattenuation $(<80$ Hounsfield units) suggestive of thrombus. The patients
\end{abstract}

without vulnerable AAA were classified as no/simple AAA group. The characteristics of diffusion-weighted MRI (DWI) lesions were analyzed in terms of the number and size of the lesions, and the involved vascular territories. Results: A total of 63 cryptogenic stroke patients were included in this study. Vulnerable AAA was observed in 15 (23.8\%) patients. The patients with vulnerable AAA were older than those with no/ simple AAA $(p=0.026)$. DWI analysis revealed that the vulnerable AAA group had a greater chance of having multiple and small lesions in multiple vascular territories that were mainly located in cortical and border-zone regions than the no/simple AAA group. Multiple logistic regression analysis showed that age (odds ratio 1.17; $95 \%$ confidence interval 1.02-1.34) and multiple small lesions in multiple vascular territories (odds ratio 33.18; 95\% confidence interval 4.26258.45) were independently associated with vulnerable AAA. Conclusion: Vulnerable AAA is independently associated with a DWI pattern characterized by multiple small scattered lesions in multiple vascular territories in conjunction with age. It may help determine stroke mechanism quickly and easily, and provide more information about the pathomechanism of vulnerable AAA-related stroke.

Copyright $\odot 2012$ S. Karger AG, Basel

Oh Young Bang, MD, PhD

Department of Neurology, Samsung Medical Center

Sungkyunkwan University

50 Irwon-dong, Gangnam-gu, Seoul 135-710 (South Korea)

Tel. +82 23410 3599, E-Mail nmboy@unitel.co.kr 


\section{Introduction}

Aortic arch atheroma (AAA) is first seen in early adulthood, and the severity increases with advancing age [1]. Since the first report in the 1990s, AAA has been considered to be associated with ischemic stroke [2-4]. Especially vulnerable AAA, which is defined as being $\geq 4 \mathrm{~mm}$ in thickness and having ulceration or mobile component, has been linked with cryptogenic ischemic stroke, stroke recurrence, and all vascular events [5-7]. However, despite its well-known role as a risk factor for stroke, research focused on the mechanism or characteristics of stroke caused by AAA is insufficient.

Diffusion-weighted MRI (DWI) is the most sensitive tool to detect not only fresh ischemic lesions that cannot be detected by CT or conventional MRI [8], but also silent infarct not commonly associated with clinical deficits [9]. Therefore, analyzing lesion pattern using DWI may provide an instructive clue in our understanding of the pathogenesis of cerebral infarcts. However, only few studies have investigated lesion pattern of acute stroke that resulted from AAA using CT or conventional MRI [10, $11]$.

Transesophageal echocardiography (TEE) has been used to evaluate the presence and severity of AAA [5]. However, because of its semi-invasive nature, it is difficult to apply to all patients. The recently developed multidetector row computed tomography (MDCT) is a powerful tool that enables rapid and specific diagnosis of aortic pathology [12]. Recent studies demonstrated the usefulness of MDCT over TEE for detection of AAA [13$15]$.

The aim of the present study was to identify clinical and radiological features in acute stroke patients associated with vulnerable AAA detected by MDCT. This may help physicians understand the mechanism of stroke caused by vulnerable AAA.

\section{Methods}

\section{Patient Selection and Evaluation}

Our analysis was performed on data collected from a prospective registry of patients who were admitted for acute cerebral infarction to a university medical center from September 2008 through May 2011. The inclusion criteria for this study were: (a) focal neurologic deficits presented within 7 days of the onset of symptoms, (b) acute ischemic lesions on DWI, and (c) conducting a cardioaortic evaluation using MDCT. Among 439 patients who met inclusion criteria, 376 were excluded because of having an evident stroke etiology by revised Trial of Org 10172 in Acute Stroke Treatment classification (fig. 1) [16]. The stroke mecha- nisms were diagnosed by consensus of two stroke neurologists (S.J.K and J.H.). The local institutional reviewer boards approved the study, and all patients were given informed consent.

Stroke Workup and Image Analysis

Demographic data, medical history of hypertension, stroke, transient ischemic attack, diabetes mellitus, hyperlipidemia and smoking history were systemically acquired. All patients underwent standardized diagnostic workup (12-lead electrocardiography, routine blood test with hematology included) and brain MRI (3.0 T, Achieva, Philips Medical systems). Hemostatic markers of prothrombotic tendency, including antiphospholipid antibodies (anticardiolipid antibody, lupus anticoagulants, and $\beta_{2}$-glycoprotein-1 antibody), were measured in patients younger than 50 years old. The typical MRI protocol included at least DWI, FLAIR, and vascular images (3-D time-of-flight MRA and contrast-enhanced MRA including extracranial internal cerebral artery and vertebral artery). The DWI parameters were as follows: repetition time, 2,550 ms; echo time, $75 \mathrm{~ms}$; matrix, $128 \times 128$; 3 directions; field of view, $24 \mathrm{~cm}$; section thickness, $5 \mathrm{~mm}$; intersection gap, $2 \mathrm{~mm}$. DWI was obtained with $b$ values of 0 and $1,000 \mathrm{~s} / \mathrm{mm}^{2}$. The mapping of lesions on the $\mathrm{T}_{1}$-MRI template and the visual comparative analysis of MRI data was achieved by using free software (MRIcro, version 1.04 build 1).

The characteristics of DWI lesions were analyzed in terms of the number (single vs. multiple) and size of the lesions, and the involved vascular territories. The size of each lesion was assessed based on the maximum diameter, and each lesion was divided into small or large lesion by $1.5 \mathrm{~cm}$. The largest size of lesion for each patient $(<1.5,1.5-3.0$, and $>3.0 \mathrm{~cm})$ on DWI was also evaluated [7]. The involvement of multiple vascular territories was defined by multiple ischemic lesions in (1) unilateral anterior and posterior circulation, (2) bilateral anterior circulation, or (3) bilateral anterior and posterior circulation. Two authors (S.R. and H.J.N.) who were blinded to patients' information reviewed the DWI data by consensus.

\section{AAA Evaluation Using MDCT}

MDCT was conducted with the use of a 64-slice multidetector row computed tomography scanner (Aquilion 64, Toshiba Medical Systems, Otawara, Japan) or a 128-slice dual-source CT system (Somatom Definition Flash, Siemens Medical Solutions, Forchheim, Germany). All scans were performed with electrocardiogram-gated dose modulation. A standard scanning protocol was applied with $64 \times 0.5 \mathrm{~mm}$ section collimation, $0.4 \mathrm{~s}$ tube rotation time, $120 \mathrm{kV}$ tube voltage, and a $400-\mathrm{mA}$ tube current. All scans were conducted with electrocardiogram-gated dose modulation. For CT scanning using a 64-slice CT scanner, approximately 65 $\mathrm{ml}$ of a nonionic contrast medium (Iomeron, $300 \mathrm{mg} \mathrm{I} / \mathrm{ml}$; Bracco $\mathrm{SpA}$, Milan, Italy) was intravenously injected $(4 \mathrm{ml} / \mathrm{s})$, after which $30 \mathrm{ml}$ of mixed normal saline and contrast medium (30\% contrast medium and $70 \%$ normal saline) was administered at a rate of $3 \mathrm{ml} / \mathrm{s}$. For CT scanning using a 128-slice dual-source scanner, approximately $70 \mathrm{ml}$ of a nonionic contrast material (Iomeprol, $350 \mathrm{mg} \mathrm{I} / \mathrm{ml}$; Bracco SpA) was administrated intravenously at 4 $\mathrm{ml} / \mathrm{s}$, followed by $40 \mathrm{ml}$ of saline at $4 \mathrm{ml} / \mathrm{s}$. Delayed, nongated scanning was conducted from the upper border of the ascending aorta to the descending thoracic aorta, including the whole heart, for identification of AAA. 


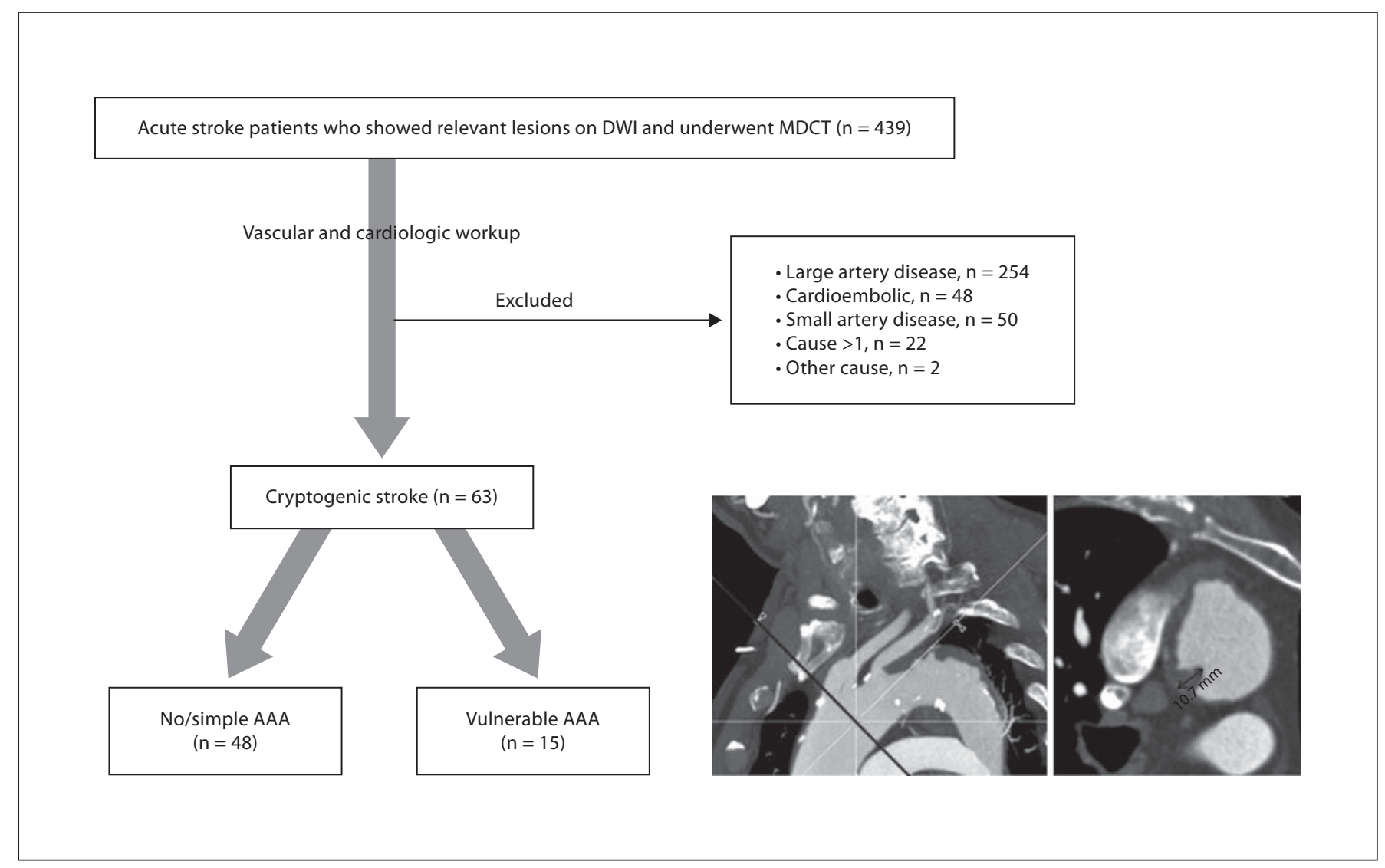

Fig. 1. Patient selection and typical MDCT findings of vulnerable AAA. Oblique sagittal (left) and coronal (right) images of aorta show a 10.7-mm-thick soft plaque (35 Hounsfield units). The coronal view is reconstructed along the black line in the oblique sagittal image.

The definition of vulnerable AAA was the presence of aortic plaques in the ascending aorta or proximal arch which met at least one of the following criteria (modified from TEE criteria): (i) at least $6 \mathrm{~mm}$ thick adjacent to the aortic wall with transverse projection; (ii) ulcerated plaque, or (iii) soft plaque [13]. Typical MDCT findings of vulnerable AAA are shown in figure 1 . In terms of plaque thickness, we chose the $6 \mathrm{~mm}$ thickness criterion for vulnerable AAA rather than $4 \mathrm{~mm}$ which most previous studies with TEE used [5]. Since MDCT assessed maximum wall size and not intima-media thickness as TEE, we added $2 \mathrm{~mm}$, which was known as aortic wall thickness in healthy individuals [17]. Soft plaque was defined as the presence of clearly visualized area of hypoattenuation ( $<80$ Hounsfield units) suggestive of thrombus $[18,19]$. The patients without vulnerable AAA were classified as no/simple AAA group. All MDCT results were reviewed by a single experienced radiologist blinded to the clinical data using a 3-D workstation (Aquarius Workstation; TeraRecon Inc., San Mateo, Calif., USA).

\section{Statistical Analysis}

We analyzed the differences between the groups using Pearson's $\chi^{2}$ test or and Fisher's exact tests for categorical variables, and a Mann-Whitney U test for continuous variables. In addition, multivariate logistic regression analysis was performed to predict the independent contribution of factors in vulnerable AAA. Variables from univariate analyses at $\mathrm{p}<0.2$ were considered to represent explanatory variables, and were entered together into multivariate analysis. A p value $<0.05$ was considered statistically significant. All statistical analyses were conducted using commercially available software (SPSS for windows, version 13.0; SPSS Inc, Chicago, Ill., USA).

\section{Results}

A total of 63 cryptogenic stroke patients were included in this study: 42 men and 21 women, mean age $64.7 \pm$ 11.9 years (range $35-80$ ). Vulnerable AAA was observed in $15(23.8 \%)$ patients. Thirteen patients had $\geq 6-\mathrm{mm}-$ thick plaques, 7 had ulceration, and 10 had soft plaques. The baseline characteristics of the patients depending on 
Table 1. Baseline characteristics according to the presence of vulnerable AAA in patients with cryptogenic stroke

\begin{tabular}{|c|c|c|c|}
\hline & \multicolumn{2}{|l|}{ Vulnerable AAA $^{1}$} & \multirow[t]{2}{*}{$\mathrm{p}$} \\
\hline & presence $(n=15)$ & absence $(n=48)$ & \\
\hline Male gender & $12(80.0)$ & $30(62.5)$ & 0.209 \\
\hline Age, years & $71(67-76)$ & $65(53-73)$ & 0.026 \\
\hline \multicolumn{4}{|l|}{ Risk factors } \\
\hline Hypertension & $12(80.0)$ & $26(54.2)$ & 0.074 \\
\hline Diabetes & $3(20.0)$ & $10(20.8)$ & $>0.999$ \\
\hline Hyperlipidemia & $7(46.7)$ & $16(33.3)$ & 0.349 \\
\hline Current smoker & $8(53.3)$ & $12(25.0)$ & 0.057 \\
\hline Previous stroke/TIA & $3(20.0)$ & $8(16.7)$ & 0.714 \\
\hline \multicolumn{4}{|l|}{ Laboratory findings } \\
\hline Total cholesterol, mg/dl & $166(149-184)$ & $171(154-196)$ & 0.425 \\
\hline Triglyceride, $\mathrm{mg} / \mathrm{dl}$ & $97(73-138)$ & $101(83-138)$ & 0.771 \\
\hline LDL-C, mg/dl & $103(86-114)$ & $111(86-125)$ & 0.324 \\
\hline $\mathrm{HDL}-\mathrm{C}, \mathrm{mg} / \mathrm{dl}$ & $46(38-53)$ & $45(38-56)$ & 0.554 \\
\hline Lipoprotein(a), mg/dl & $25.7(8.9-36.0)$ & $24.5(13.7-35.1)$ & 0.591 \\
\hline \multicolumn{4}{|l|}{ Pre-stroke medication } \\
\hline Antiplatelet & $7(46.7)$ & $15(31.3)$ & 0.274 \\
\hline Statin & $4(26.7)$ & $10(20.8)$ & 0.725 \\
\hline ACEi/ARB & $2(13.3)$ & $10(20.8)$ & 0.714 \\
\hline
\end{tabular}

Values are presented as median (interquartile range) or number (\%). TIA = Transient ischemic attack; LDL-C = low-density lipoprotein cholesterol; HDL-C = high-density lipoprotein cholesterol; $\mathrm{ACEi}=$ angiotensin-converting enzyme inhibitor; $\mathrm{ARB}=$ angiotensin receptor blocker.

${ }^{1}$ Defined by the presence of aortic plaques in the ascending aorta or proximal arch with thrombus, ulceration, or $\geq 6 \mathrm{~mm}$ in wall thickness.

the presence of vulnerable AAA are presented in table 1. The patients with vulnerable AAA were older than those with no/simple AAA $(\mathrm{p}=0.026)$. Among vascular risk factors, a history of hypertension and current smoking were recorded more frequently in the patients with vulnerable AAA, but did not reach statistical significance. Other clinical and laboratory findings did not differ between the two groups.

The DWI features classified by vulnerable AAA are demonstrated in table 2. As shown in figure 2, the vulnerable AAA group had more lesions than the no/simple AAA group (median lesion number per patient, 4 vs. 1; $p=0.001)$. Thirteen out of 15 patients (86.7\%) with vulnerable AAA had multiple lesions, but more than half of patients with no/simple AAA had only one lesion ( $\mathrm{p}=$ 0.005). In terms of lesion size, most of patients belonging to the vulnerable AAA group had only small lesions. On the contrary, 31 out of 48 patients (64.6\%) in the no/simple AAA group had at least one large lesion $(\mathrm{p}=0.020)$. Similarly, the largest lesion size of an individual patient was smaller in the vulnerable AAA group $(\mathrm{p}=0.019)$.
When considering involved vascular territory on DWI, more than $70 \%$ in patients with vulnerable AAA had involvement of multiple vascular territories, whereas single vascular territory was most frequently involved in the no/ simple AAA group $(\mathrm{p}<0.001)$.

To further characterize the lesion pattern on DWI in patients with cryptogenic stroke according to the status of AAA, aforementioned features including lesion multiplicity, size, and involved vascular territory were combined. The most common lesion pattern among patients with vulnerable AAA was multiple small lesions in multiple vascular territories. Conversely, involvement of single vascular territory with various combinations was most often observed in no/simple AAA group $(\mathrm{p}<0.001)$. As shown in figure 3 , the majority of lesions on DWI in patients with vulnerable AAA were located in cortical and border-zone regions.

Multivariate logistic regression analysis was performed to further evaluate independent predictors for the presence of vulnerable AAA in patients with cryptogenic stroke (table 3 ). As a result, age (per 1 year increase, 


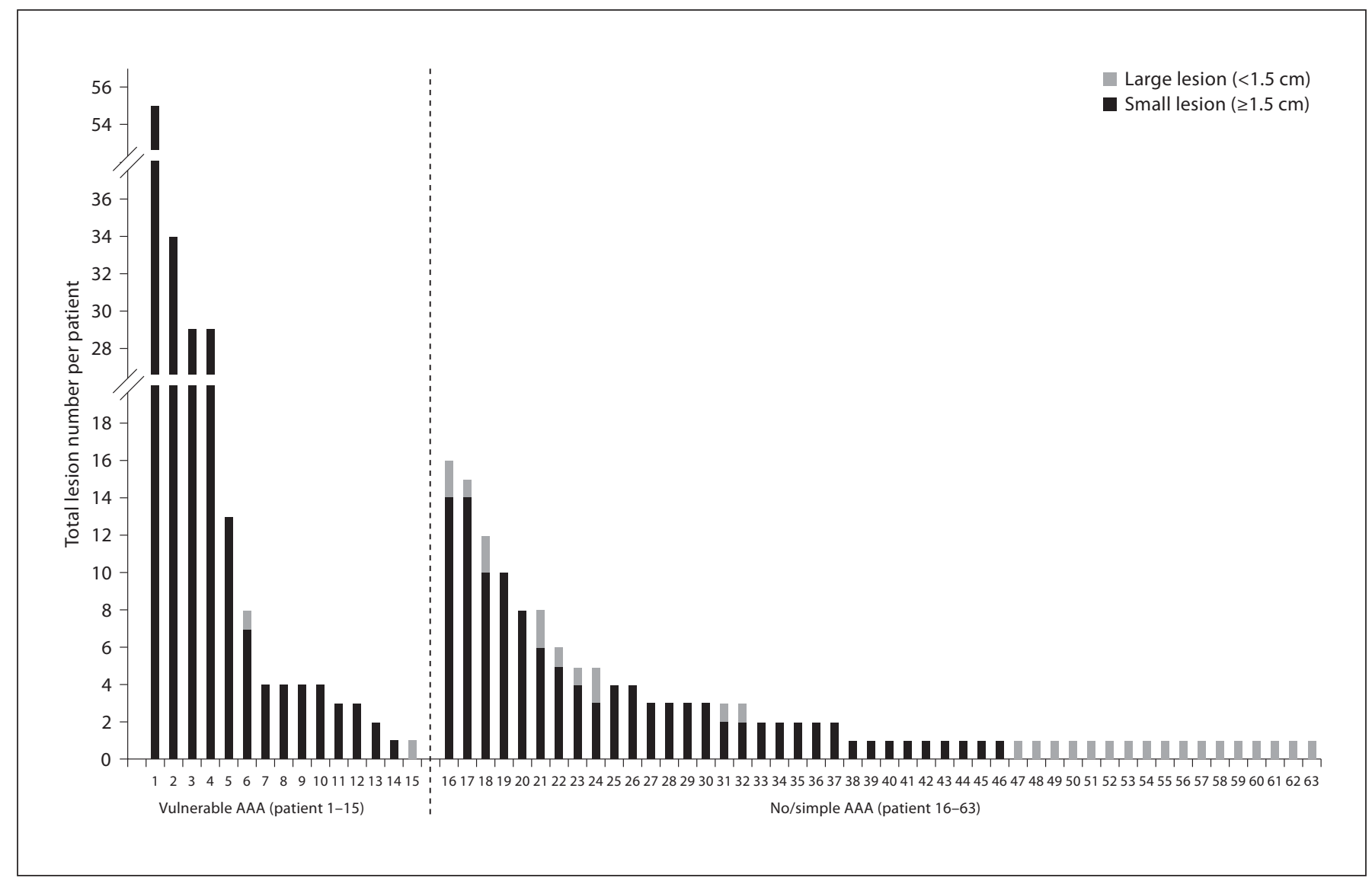

Fig. 2. Distribution of number and size of lesions on DWI in each patient. Patients 1-15 had vulnerable AAA, and patients 16-63 had no/simple atheroma.

OR 1.17; 95\% CI 1.02-1.34) and multiple small lesions in multiple vascular territories (OR 33.18; 95\% CI 4.26258.45) were independently associated with vulnerable AAA.

\section{Discussion}

AAA has been found in $60 \%$ of patients 60 years of age or older with ischemic stroke [5]. It is well known that AAA is associated with ischemic stroke [20,21]. However, AAA has received limited attention as an embolic source to the brain compared with atrial fibrillation and severe carotid stenosis [1]. In classification systems of ischemic stroke subtype, even vulnerable AAA is just regarded as an embolic source with a low or uncertain risk for ischemic stroke [16]. Nevertheless, many lines of evidence have suggested that AAA is a source of thromboembo- lism to the cerebral circulation, not simply an index of the extent of arterial disease, and therefore risk of stroke $[1$, 22-25].

Knowledge of the clinical and radiological features of cryptogenic stroke will help physicians understand the pathogenic mechanisms involved in stroke development which influenced choice of management, stroke prognosis, and risk of recurrence [26, 27]. Because the pattern of lesions identified by DWI has been correlated with the underlying pathogenic mechanisms of stroke, it may be important to analyze DWI features to find the hidden cause in patients with cryptogenic stroke [2830].

In this study, the most common DWI pattern of stroke associated with vulnerable AAA was multiple and small lesions in multiple vascular territories which were mainly located in cortical and border-zone regions. It has been suggested that multiple acute lesions in stroke are em- 
Table 2. Characteristics of DWI lesions according to the presence of vulnerable AAA in patients with cryptogenic stroke

\begin{tabular}{|c|c|c|c|}
\hline & \multicolumn{2}{|l|}{ Vulnerable AAA } & \multirow[t]{2}{*}{$\mathrm{p}$} \\
\hline & presence $(n=15)$ & absence $(n=48)$ & \\
\hline Total lesion number per patient & $4(3-29)$ & $1(1-3)$ & 0.001 \\
\hline Lesion multiplicity & & & 0.005 \\
\hline Single lesion & $2(13.3)$ & $26(54.2)$ & \\
\hline Multiple lesions & $13(86.7)$ & $22(45.8)$ & \\
\hline Lesion size & & & 0.020 \\
\hline Small lesions only & $13(86.7)$ & $17(35.4)$ & \\
\hline Small + large lesions & $1(6.7)$ & $9(18.8)$ & \\
\hline Large lesions only & $1(6.7)$ & $22(45.8)$ & \\
\hline Largest lesion size, $\mathrm{cm}$ & & & 0.019 \\
\hline$<1.5$ & $13(86.7)$ & $22(45.8)$ & \\
\hline $1.5-3.0$ & $1(6.7)$ & $13(27.1)$ & \\
\hline$>3.0$ & $1(6.7)$ & $13(27.1)$ & \\
\hline Involved vascular territory & & & $<0.001$ \\
\hline Single vascular territory & $4(26.7)$ & $42(87.5)$ & \\
\hline Multiple vascular territories & $11(73.3)$ & $6(12.5)$ & \\
\hline Bilateral anterior circulation & 5 & 4 & \\
\hline Unilateral anterior + posterior circulation & 2 & 2 & \\
\hline Bilateral anterior + posterior circulation & 4 & 0 & \\
\hline Lesion pattern & & & $<0.001$ \\
\hline Single vascular territory & $4(26.7)$ & $42(87.5)$ & \\
\hline Single vascular territory, single and small lesion & 1 & 9 & \\
\hline Single vascular territory, single and large lesion & 1 & 17 & \\
\hline Single vascular territory, multiple small lesions & 2 & 9 & \\
\hline Single vascular territory, multiple large + small lesions & 0 & 7 & \\
\hline Multiple vascular territories, multiple large + small lesions & $1(6.7)$ & $2(4.2)$ & \\
\hline Multiple vascular territories, multiple small lesions & $10(66.7)$ & $4(8.3)$ & \\
\hline
\end{tabular}

Values are presented as median (interquartile range) or number (\%).

Table 3. Multiple logistic regression for the presence of vulnerable AAA in patients with cryptogenic stroke

\begin{tabular}{lccc}
\hline & Crude OR & Multivariate OR & p \\
\hline Age (per 1-year increase) & $1.10(1.02-1.20)$ & $1.17(1.02-1.34)$ & 0.022 \\
Hypertension & $3.39(0.85-13.54)$ & - & \\
Current smoker & $3.43(1.03-11.46)$ & - & 0.003 \\
DWI lesion pattern & & & \\
$\quad$ Single vascular territory & Ref. & Ref. & \\
$\quad$ Multiple vascular territories, multiple large + small lesions & $5.25(0.39-71.42)$ & $42.32(0.77-2,312.79)$ & 0.134 \\
$\quad$ Multiple vascular territories, multiple small lesions & $26.25(5.58-123.43)$ & $33.18(4.26-258.45)$ & 0.002 \\
\hline
\end{tabular}

bolic in origin [28], and a recent study revealed that AAA containing mobile components is independently associated with the multiple lesions in multiple vascular territories, which is consistent with our finding [7]. It could be explained by plaque rupture that can scatter multiple emboli or the breakup of an embolus. In a transcranial Doppler study, the incidence of microembolic signals was associated with vulnerable AAA, suggesting that microemboli are originating from AAA [24]. Interestingly, our DWI lesion pattern analysis showed that most of the le- 


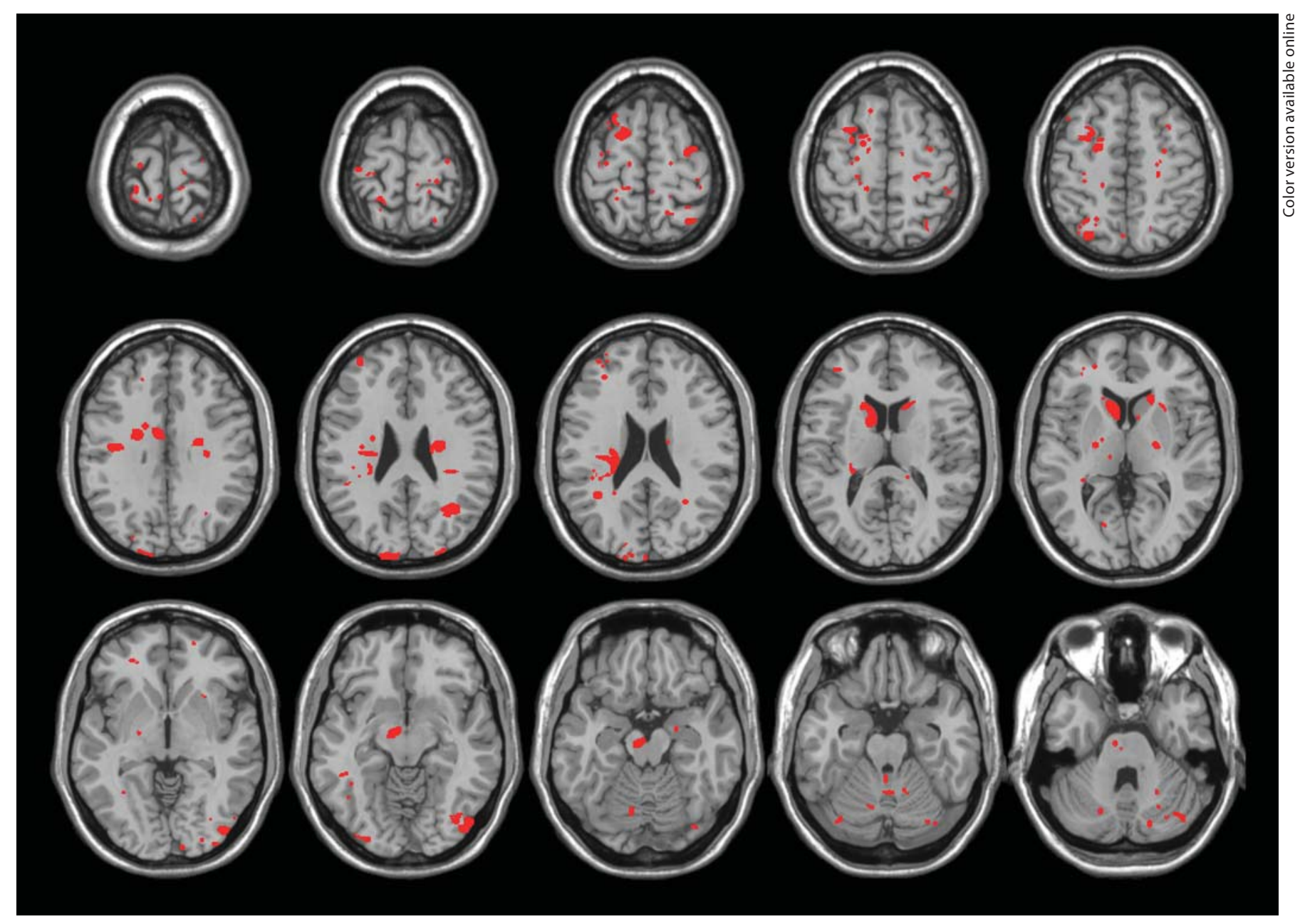

Fig. 3. Summation map of all DWI imaging in patients with vulnerable AAA. The majority of lesions are small and located in cortical and border-zone regions. One patient with a single and large lesion in a single vascular territory is not shown on this map because the lesion obscured many other lesions.

sions with vulnerable AAA were small and located in cortical and border-zone regions. Our DWI results are in line with the previous autopsy study investigating cholesterol emboli that can be derived from vulnerable AAA [31].

Besides the lesion pattern on DWI, age was also independently related to vulnerable AAA. It is well known that the incidence and severity of AAA increases with age $[32,33]$. Among vascular risk factors, hypercholesterolemia, cigarette smoking, hypertension, and diabetes mellitus have also been associated with AAA [1]. In this study, there was a trend for hypertension and smoking in patients with vulnerable AAA, but it did not reach statistical significance, presumably due to the small sample size.
In this study, we used MDCT for detection of AAA. Although TEE has long been used for evaluation of the aortic arch, there are several advantages of MDCT over TEE. First, MDCT seems to be much more helpful in measuring the thickness of AAA, finding ulceration, and examining its components [13]. Second, MDCT is not an invasive procedure compared to TEE, which is semi-invasive and has a relatively high procedure failure rate $[14,34]$. Third, TEE is imperfect in evaluating the aortic arch due to a blind spot [35]. Lastly, in addition to detecting AAA, MDCT can provide more comprehensive information in demonstrating coronary artery disease and other possible sources of cardioembolism [34, 36]. 
It is important to note that this study had several limitations. First, the results should be interpreted with caution because they were based on data obtained from a single center with a small sample size. Accordingly, our results need independent confirmation through future prospective stroke studies. Second, it should be noted that the vulnerable AAA criteria based on MDCT lack validity. However, a recent study evaluating AAA in embolic stroke using MDCT used TEE criteria with modification like our study, and showed a significant association between possibly embolic stroke and AAA [13].

In conclusion, vulnerable AAA is independently associated with a DWI pattern characterized by multiple small scattered lesions in multiple vascular territories in conjunction with age. It may help determine stroke mechanism quickly and easily, and provide more information about the pathomechanism of vulnerable AAA-related stroke.

\section{Acknowledgement}

This study was supported by the Korean Healthcare Technology R\&D Project, Ministry of Health and Welfare (A110208).

\section{Disclosure Statement}

None.

\section{References}

1 Macleod MR, Amarenco P, Davis SM, Donnan GA: Atheroma of the aortic arch: an important and poorly recognised factor in the aetiology of stroke. Lancet Neurol 2004;3: 408-414.

-2 Karalis DG, Chandrasekaran K, Victor MF, Ross JJ Jr, Mintz GS: Recognition and embolic potential of intraaortic atherosclerotic debris. J Am Coll Cardiol 1991;17:73-78.

$\checkmark 3$ Amarenco P, Duyckaerts C, Tzourio C, Henin D, Bousser MG, Hauw JJ: The prevalence of ulcerated plaques in the aortic arch in patients with stroke. N Engl J Med 1992;326: 221-225.

4 Di Tullio MR, Sacco RL, Gersony D, Nayak H, Weslow RG, Kargman DE, Homma S: Aortic atheromas and acute ischemic stroke: a transesophageal echocardiographic study in an ethnically mixed population. Neurol ogy 1996;46:1560-1566.

5 Amarenco P, Cohen A, Tzourio C, Bertrand B, Hommel M, Besson G, Chauvel C, Touboul PJ, Bousser MG: Atherosclerotic disease of the aortic arch and the risk of ischemic stroke. N Engl J Med 1994;331:1474-1479.

$\checkmark 6$ Atherosclerotic disease of the aortic arch as a risk factor for recurrent ischemic stroke. The French study of aortic plaques in stroke group. N Engl J Med 1996;334:1216-1221.

$\checkmark 7$ Ueno Y, Kimura K, Iguchi Y, Shibazaki K, Inoue $\mathrm{T}$, Hattori $\mathrm{N}$, Urabe $\mathrm{T}$ : Mobile aortic plaques are a cause of multiple brain infarcts seen on diffusion-weighted imaging. Stroke 2007;38:2470-2476.

>8 Singer MB, Chong J, Lu D, Schonewille WJ, Tuhrim S, Atlas SW: Diffusion-weighted MRI in acute subcortical infarction. Stroke 1998;29:133-136.
9 Lovblad KO, Pluschke W, Remonda L, Gruber-Wiest D, Do DD, Barth A, Kniemeyer HW, Bassetti C, Mattle HP, Schroth G: Diffusion-weighted MRI for monitoring neurovascular interventions. Neuroradiology 2000;42:134-138.

10 Falcone RA, Shapiro EP, Jangula JC, Johnson CJ: Transesophageal echocardiographic findings in subcortical and cortical stroke. Am J Cardiol 2000;85:121-124, A129.

$\checkmark 11$ Meissner I, Khandheria BK, Sheps SG, Schwartz GL, Wiebers DO, Whisnant JP, Covalt JL, Petterson TM, Christianson TJ, Agmon Y: Atherosclerosis of the aorta: risk fac tor, risk marker, or innocent bystander? A prospective population-based transesophageal echocardiography study. J Am Coll Cardiol 2004;44:1018-1024.

12 Johnson TR, Nikolaou K, Wintersperger BJ, Knez A, Boekstegers P, Reiser MF, Becker CR: ECG-gated 64-MDCT angiography in the differential diagnosis of acute chest pain. AJR Am J Roentgenol 2007; 188:76-82.

13 Ko Y, Park JH, Yang MH, Ko SB, Choi SI, Chun EJ, Han MK, Bae HJ: Significance of aortic atherosclerotic disease in possibly embolic stroke: 64-multidetector row computed tomography study. J Neurol 2010;257:699705.

14 Hussain SI, Gilkeson RC, Suarez JI, Tarr R, Schluchter M, Landis DM, Zaidat OO: Comparing multislice electrocardiogram-gated spiral computerized tomography and transesophageal echocardiography in evaluating aortic atheroma in patients with acute ischemic stroke. J Stroke Cerebrovasc Dis 2008; 17:134-140.
15 Kim SJ, Choe YH, Park SJ, Kim GM, Chung CS, Lee KH, Bang OY: Routine cardiac evaluation in patients with ischaemic stroke and absence of known atrial fibrillation or coronary heart disease: transthoracic echocardiography vs. multidetector cardiac computed tomography. Eur J Neurol 2012;19:317323.

16 Ay H, Furie KL, Singhal A, Smith WS, Sorensen AG, Koroshetz WJ: An evidencebased causative classification system for acute ischemic stroke. Ann Neurol 2005;58: 688-697.

17 Jeltsch M, Klass O, Klein S, Feuerlein S, Aschoff AJ, Brambs HJ, Hoffmann MH: Aortic wall thickness assessed by multidetector computed tomography as a predictor of coronary atherosclerosis. Int J Cardiovasc Imaging 2009;25:209-217.

18 Tenenbaum A, Garniek A, Shemesh J, Fisman EZ, Stroh CI, Itzchak Y, Vered Z, Motro M: Dual-helical CT for detecting aortic atheromas as a source of stroke: comparison with transesophageal echocardiography. Radiology 1998;208:153-158.

19 Carrascosa PM, Capunay CM, Garcia-Merletti P, Carrascosa J, Garcia MF: Characterization of coronary atherosclerotic plaques by multidetector computed tomography. Am J Cardiol 2006;97:598-602.

20 Kronzon I, Tunick PA: Aortic atherosclerotic disease and stroke. Circulation 2006;114: 63-75.

21 Yoshimura S, Toyoda K, Kuwashiro T, Koga M, Otsubo R, Konaka K, Naganuma M, Matsuoka H, Naritomi H, Minematsu K: Ulcerated plaques in the aortic arch contribute to symptomatic multiple brain infarction. J Neurol Neurosurg Psychiatry 2010;81:13061311. 
-22 Jones EF, Kalman JM, Calafiore P, Tonkin AM, Donnan GA: Proximal aortic atheroma. An independent risk factor for cerebral ischemia. Stroke 1995;26:218-224.

-23 Tunick PA, Perez JL, Kronzon I: Protruding atheromas in the thoracic aorta and systemic embolization. Ann Intern Med 1991;115: 423-427.

-24 Rundek T, Di Tullio MR, Sciacca RR, Titova IV, Mohr JP, Homma S, Sacco RL: Association between large aortic arch atheromas and high-intensity transient signals in elderly stroke patients. Stroke 1999;30:2683-2686.

-25 Viguier A, Pavy le Traon A, Massabuau P, Valton L, Larrue V: Asymptomatic cerebral embolic signals in patients with acute cerebral ischaemia and severe aortic arch atherosclerosis. J Neurol 2001;248:768-771.

-26 Bang OY, Lee PH, Yeo SH, Kim JW, Joo IS, Huh K: Non-cardioembolic mechanisms in cryptogenic stroke: Clinical and diffusionweighted imaging features. J Clin Neurol 2005; $1: 50-58$.
27 Bang OY, Lee PH, Joo SY, Lee JS, Joo IS, Huh $\mathrm{K}$ : Frequency and mechanisms of stroke recurrence after cryptogenic stroke. Ann Neurol 2003;54:227-234.

-28 Baird AE, Lovblad KO, Schlaug G, Edelman RR, Warach S: Multiple acute stroke syndrome: marker of embolic disease? Neurology 2000;54:674-678.

29 Lee PH, Bang OY, Oh SH, Joo IS, Huh K: Subcortical white matter infarcts: comparison of superficial perforating artery and internal border-zone infarcts using diffusion-weighted magnetic resonance imaging. Stroke 2003;34:2630-2635.

30 Fujimoto S, Toyoda K, Jinnouchi J, Yasaka M, Kitazono T, Okada Y: Differences in diffusion-weighted image and transesophageal echocardiographical findings in cardiogenic, paradoxical and aortogenic brain embolism. Cerebrovasc Dis 2011;32:148-154.

31 Ezzeddine MA, Primavera JM, Rosand J, Hedley-Whyte ET, Rordorf G: Clinical characteristics of pathologically proved cholesterol emboli to the brain. Neurology 2000; 54:1681-1683.
2 Strong JP, Restrepo C, Guzman M: Coronary and aortic atherosclerosis in new orleans. II. Comparison of lesions by age, sex, and race. Lab Invest 1978;39:364-369.

33 Sen S, Oppenheimer SM, Lima J, Cohen B: Risk factors for progression of aortic atheroma in stroke and transient ischemic attack patients. Stroke 2002;33:930-935.

34 Hur J, Kim YJ, Lee HJ, Ha JW, Heo JH, Choi EY, Shim CY, Kim TH, Nam JE, Choe KO, Choi BW: Cardiac computed tomographic angiography for detection of cardiac sources of embolism in stroke patients. Stroke 2009; 40:2073-2078.

35 Schneider AT, Hsu TL, Schwartz SL, Pandian NG: Single, biplane, multiplane, and three-dimensional transesophageal echocardiography. Echocardiographic-anatomic correlations. Cardiol Clin 1993;11:361-387.

36 Kim SJ, Choe YH, Bang OY: Are stroke biomarkers seeing brain vessels in patients with ischemic stroke? A C-reactive protein and homocysteine study. Stroke 2011;42:14641468. 